\title{
An external auditory canal lesion: lobular capillary Hemangioma
}

\begin{abstract}
Hemangiomas are vascular tumors and they are common in the head and neck region, but substantially rarely seen in the ear. In this report, we present a female patient who suffered from an external auditory canal placed lesion. After the radiological evaluations, lesion was excised with clear margins. Postoperative histopathogical diagnosis was lobular capillary hemangioma. We discussed the preoperative surveys and operative assessment of this clinical entity.
\end{abstract}

Keywords: hemangioma, lobular capillary hemangioma, external ear
Volume I Issue I - 2014

\section{Murat Topdag,Ahmet Mutlu, Fatih Sari and Murat Ozturk \\ Department of Otorhinolaryngology, Kocaeli University Faculty} of Medicine, Turkey

Correspondence: Ahmet Mutlu, Department of Otorhinolaryngology, Kocaeli University Faculty of Medicine, KBB Anabilim Dali, 4I 380, Kocaeli, Turkey, Tel +90 5355003650 , Fax+90 262 3037003, Email ahmutlul 988@gmail.com

Received: October 26, 2014 | Published: January 02, 2015
Abbreviations: CT, computerized tomography; MRI, magnetic resonance imaging; DSA, digital subtraction angiography; CSF, cerebro spinal fluid

\section{Introduction}

Hemangiomas are benign vascular tumors and they can occur quite commonly in the head and neck region. ${ }^{1-3}$ Lobular capillary hemangioma (formerly named Pyogenic Granuloma) is a rare subtype that can be encountered in the skin and mucous membranes. ${ }^{4}$ In the English literature, most reports include lesions of the oral cavity, face and nasal cavities. Although the relationship with female sex hormones (most lesions present during pregnancy), chronic irritation from oral implants, trauma due to nasal packing has been suggested, the exact etiology is still unclear., ${ }^{2,4}$ The external ear canal is very uncommon location for a capillary hemangioma. ${ }^{5}$ We wanted to share our experience on a massive external auditory canal mass that diagnosed as a lobular capillary hemangioma with the written consent of patient and her family.

\section{Case report}

A 19 year-old female patient with mild mental retardation was referred to our clinic due to a red, pulsatile and painful lesion located in the left ear (Figure 1A). She had been treated with the ciprofloxacin drops for the chronic otitis media and there was no history of trauma, pregnancy or facial nerve dysfunction. On the pure tone audiometer right ear: $10 \mathrm{~dB}$, left ear: $75 \mathrm{~dB}$ (severe conductive hearing loss) detected. Temporal bone Computerized Tomography (CT) images showed that the soft tissue was located in the left ear canal and no bone defect was detected (Figure 1B). Magnetic resonance imaging (MRI) revealed a $30 \times 20 \times 10 \mathrm{~mm}$ vascular external ear canal mass (Figure 1C). Digital subtraction angiography (DSA) showed a lesion with delayed contrast retention, reminiscent of a hemangioma (Figure 2). Patient underwent canal wall down mastoidectomy operation and a hemangioma originating from the inferior external ear canal was excised with clean surgical margins. Early and delayed postoperative course was uneventful.

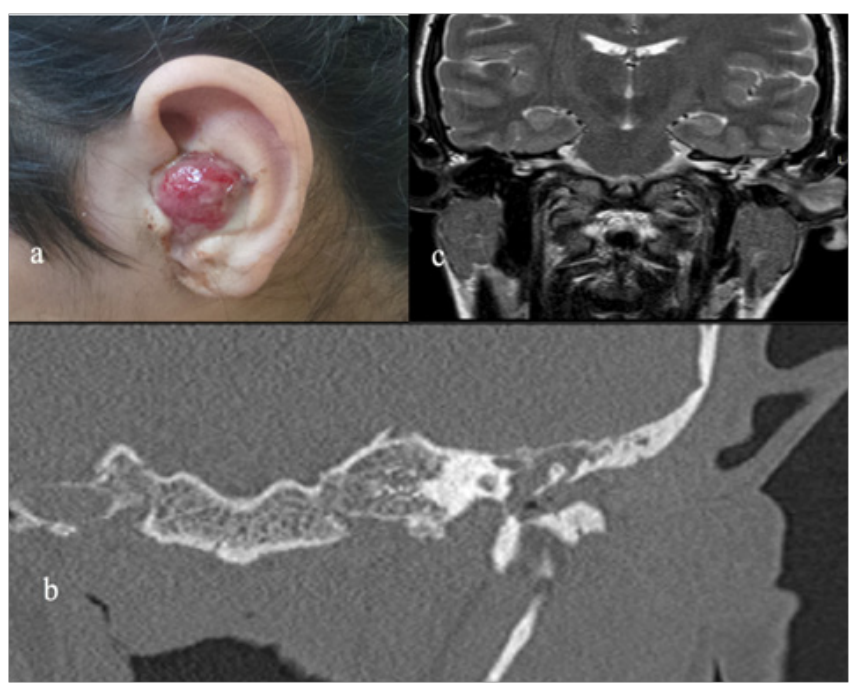

Figure I (A) External auditory canal placed lesion on left ear. (B) Coronal computed tomography of the left temporal bone, showing the soft tissue density on the external auditory canal.There is no evidence of the bone destruction. (C) Coronal of the T2-weighted magnetic resonance images of the left temporal bone, showing the high intensity of the pedinculated soft tissue placed on the external auditory canal. 


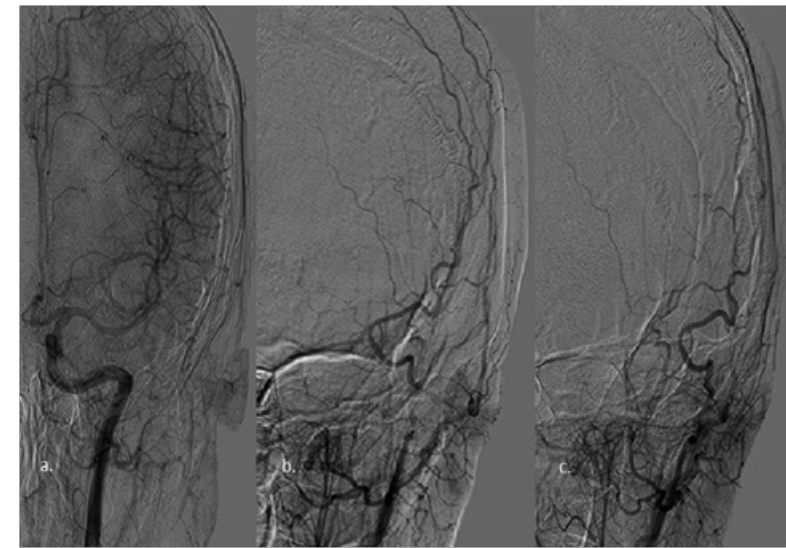

Figure 2 DSA images showing a capillary mass lesion on the left temporal bone vasculated from external carotid artery; (A) Early arterial (B) Delayed venous (C) Late venous blush of the lesion.

\section{Discussion}

External auditory canal is an uncommon location for a lobular capillary hemangioma. Although these vascular tumors usually present with pulsatile tinnitus, recurrent aural bleeding, hearing loss and a red-purple tympanic membrane, a pediculated auricular mass, such as seen in our patient, may be the main complaint. ${ }^{5}$ The differential diagnosis with these clinical findings is relatively wide including glomus tumors (glomus tympanicum, glomus jugulare), aberrant carotid artery, high jugular bulb, cholesterol granulomas and meningiomas. ${ }^{1,6}$ A soft tissue mass detected on MRI, the lack of bone destruction on $\mathrm{CT}$ and a persistent vascular blush on DSA enabled us diagnose the lesion preoperatively. Although we considered preoperative embolization to decrease the operative blood loss, it was not performed due to relatively poor arterial capillary structure on the angiography.

Treatment of these lesions is excision with clear surgical margins. Different approaches can be considered according to the location of the lesion. Small lesions can be removed with transcanal approach where as advance lesions transmastoid, translabyrinthine, middle fossa approach or combined methods must be considered. . $^{2,3}$ In our case, we preferred the transmastoid technic (canal wall down mastoidectomy) to remove the lesion. The approach was adequate, and there were no evidence for the facial paralysis or cerebro spinal fluid (CSF) leakage at postoperative period. No recurrence has been detected during late postoperative follow-ups.

\section{Acknowledgments}

None.

\section{Conflicts of interest}

The authors declare that there is no conflicts of interest.

\section{References}

1. Hecht DA, Jackson CG, Grundfast KM. Management of the middle ear hemangiomas. Am J Otolaryngol. 2001;22(5):362-366.

2. Pistorio V, De Stefano A, Petrucci AG, Achilli V Capillary haemangioma of the middle ear: a rare lesion difficult to evaluate. Acta Otorhinolaryngol Ital. 2010;31(2):109-112.

3. Spector ME, Adams ME, Arts HA. A Capillary hemangioma of the tympanic membrane. Am J Otolaryngol. 2011;32(6):615-616.

4. Kurtaran H, Uraldi C, Arki N, et al. Lobular capillary haemangioma of the middle turbinate. Acta Otolaryngol. 2006;126(4): 442-444.

5. Schild C, Kayser G, Aschendorff A, et al. Pedunculated capillary hemangioma of the external ear. Otolaryngol Head Neck Surg. 2009;140(5):764-765.

6. Hsu $\mathrm{CH}$, Chen $\mathrm{HC}$, Wang $\mathrm{CH}$. Bilateral external auditory canal pyogenic granuloma. Otolaryngol Head Neck Surg. 2008;139(4): 596-597.

7. Yasar H, Ozkul H, Somay A. A rare vascular tumor of the external auditory canal: the capillary hemangioma. Kulak Burun Bogaz Ihtis Derg. 2009; 19(4):212-215. 